\title{
A Internet como Instrumento de Pesquisa e de Aprendizagem: uma Análise a partir do Ensino de Geografia
}

\author{
The Internet as a Research Instrument and Learning: an Analysis from the Geography \\ Teaching
}

\begin{abstract}
La Internet como Instrumento de Investigación y de Aprendizaje: un Análisis a partir de la Enseñanza de Geografía
\end{abstract}

\author{
Severino Alves Coutinho ${ }^{1}$
}

\begin{abstract}
RESUMO: Este artigo está pautado num estudo voltado ao ensino de Geografia e o uso da internet como fonte de informação e de pesquisa, tendo em vista sua acessibilidade enquanto interface tecnológica importante para o desenvolvimento de atividades pedagógicas que permita a sua utilização não apenas como mera atratividade, mas, sobretudo, como veículo de comunicação que expressa em tempo real uma diversidade de imagens e informações que podem subsidiar o planejamento e motivar docentes e discentes, gerando mais qualidade no processo de ensino aprendizagem. Ademais, enquanto recurso didático tecnológico, a internet oferece um diversificado fluxo de trabalhos acadêmicos em formato digital, possibilitando a leitura e a reflexão, bem como ainda servindo como suporte teórico para estudos propostos pela disciplina. Sob esse viés de análise, esse artigo foi estruturado a partir de uma pesquisa de campo realizada na Escola Estadual Professora Ocila Bezerril, no município de Montanhas - RN, onde foram aplicados questionários aos alunos do $1^{\circ} \stackrel{0}{a}$ ano do Ensino Médio, buscando verificar se a internet tem sido utilizada como instrumento que proporciona aprendizagem no ensino de Geografia, bem como se os docentes têm orientado estudos que contemplem o uso dessa tecnologia em sala de aula. Pela análise dos dados, constatou-se que apesar dos alunos serem a favor da inserção deste recurso no contexto escolar, nem todos os educadores têm como prática lecionar Geografia em consonância com a dinâmica interativa da internet.
\end{abstract}

PALAVRAS-CHAVE: Geografia. Internet. Aprendizagem.

ABSTRACT: This article is guided in a study focused on Geography teaching and the use of the internet as a source of information and research, since its accessibility as an important technological interface for the development of pedagogical activities that allows its use not only as mere attractiveness but above all as communication vehicle that expresses in real time a diversity of images and information that can subsidize the planning and motivate teachers and students, generating more quality in the teaching-learning process. Furthermore, as a technological didactic resource, the

\footnotetext{
${ }^{1}$ Escola Estadual Professora Ocila Bezerril, Endereço: Rua São José, 449, Centro, CEP: 59198-000, Montanhas - RN, E-mail: coutinhogeo@hotmail.com.
} 
internet offers a diversified flow of academic works in digital format, providing reading and reflection, as well as serving as a theoretical support for studies proposed by the school subject. Following this perspective, this article was structured from a research carried out at Professora Ocila Bezerril State School, in the municipality of Montanhas - RN, where we applied the questionnaires to students of the 1 st grade of high school, seeking to verify if the internet has been used as a tool that provides learning in the teaching of Geography, as well as whether teachers have guided studies that contemplate the use of this technology in the classroom. By analyzing the data, we found that although the students are in favor of inserting this resource in school context, not all educators have the practice of teaching Geography in accordance with the interactive dynamics of the internet.

KEYWORDS: Geography. Internet. Learning.

RESUMEN: Este artículo está pautado en un estudio orientado a la enseñanza de Geografía y el uso de internet como fuente de información y de investigación, teniendo en vista su accesibilidad como interfaz tecnológica importante para el desarrollo de actividades pedagógicas que permita su utilización no sólo como simple atractivo pero, sobre todo, como vehículo de comunicación que expresa en tiempo real una diversidad de imágenes e informaciones que pueden subsidiar la planificación y motivar docentes y discentes, generando más calidad en el proceso de enseñanza y aprendizaje. Además, como recurso didáctico tecnológico, la internet ofrece un diversificado flujo de trabajos académicos en formato digital, posibilitando la lectura y la reflexión, así como, sirviendo como soporte teórico para estudios propuestos por la asignatura. Desde esa perspectiva, este artículo se ha estructurado a partir de una investigación realizada en la Escuela Provincial Professora Ocila Bezerril, en el municipio de Montanhas - RN, donde aplicamos los cuestionarios a los estudiantes del 1 o grado de la enseñanza media, buscando verificar si la internet se ha utilizado como una herramienta que proporciona aprendizaje en la enseñanza de la Geografía, así como si los maestros tienen estudios guiados que contemplen el uso de esta tecnología en el aula. Al analizar los datos, se descubrió que, aunque los estudiantes están a favor de introducir este recurso en el contexto escolar, no todos los educadores tienen la práctica de enseñar Geografía en consonancia con la dinámica interactiva de internet.

PALABRAS-CLAVE: Geografía. Internet. Aprendizaje.

\section{INTRODUÇÃO}

A Geografia tem um papel significativo como disciplina escolar que utiliza e explora as redes on-line, pois neste meio não existem fronteiras e a possibilidade de novos saberes é uma realidade evidenciada constantemente através da pesquisa, da análise e da reflexão sobre determinados temas educacionais.

A internet, por exemplo, abre inúmeras possibilidades de aprendizagem, mas para isso é necessário um trabalho pedagógico voltado às relações sociais no ambiente escolar, principalmente em sala de aula, onde o docente tem um desafio a cumprir, o pensar na formação do aluno e no desenvolvimento da sua autonomia, da criatividade e das novas descobertas.

Nesse sentido, o docente que utiliza tecnologia como recurso de aprendizagem estará não apenas subsidiando as aulas, mas também instigando o senso crítico dos alunos, que 
deixam de serem meros receptores para tornarem-se sujeitos participantes, que concordam ou discordam sobre o que veem e leem na internet.

O ensino de Geografia deve pautar-se em estratégias cujas propostas estejam vinculadas ao contexto sociocultural dos educandos, considerando as transformações ocorridas na sociedade com a crescente utilização da internet e suas implicações no ambiente escolar, o que supõe pensar em novos desafios para a educação, exigindo-se práticas que integrem essa tecnologia a projetos educacionais participativos e inovadores. Essa deve ser uma prática constante em que professores e alunos somem em um trabalho coletivo, numa perspectiva educacional que vise atender aos anseios da sociedade contemporânea.

Neste contexto, fez-se um levantamento bibliográfico acerca do tema, tendo como referências livros, dissertações, teses e artigos científicos, cujos autores tem se dedicado aos estudos sobre o ensino de Geografia e ao uso da internet na educação. Além disso, realizou-se uma pesquisa de campo na Escola Estadual professora Ocila Bezerril, no município de Montanhas - $\mathrm{RN}$, onde foi utilizada como instrumento metodológico a aplicação de um questionário aos alunos do $1^{\circ}$ ano do Ensino Médio, visando identificar se são realizadas atividades pedagógicas que possibilitem aprendizagem a partir da interação entre a disciplina de Geografia e a utilização da internet no cotidiano escolar.

\section{A INTERNET COMO FONTE DE PESQUISA NO ENSINO DE GEOGRAFIA}

A Geografia constitui uma importante disciplina que compõe o currículo escolar. Sua abordagem perpassa a esfera local em que docentes e discentes estão inseridos, uma vez que seu objeto de estudo é o espaço geográfico onde ocorre todo o processo de transformação desenvolvido pela sociedade, desde o surgimento de países, regiões ou cidades, bem como a produção das atividades econômicas e o desenvolvimento de diversos recursos tecnológicos, como por exemplo, o computador, o tablete e o celular. Estes, associados à internet, promoveram mudanças no cotidiano e nas relações humanas, inclusive no âmbito educacional. Nesse sentido, o uso de tecnologias como:

[...] o computador, o celular e o tablete, dentre outros dispositivos de informática, precisa ser ampliado para atender às demandas dos processos formativos e de ensino-aprendizagem na educação básica. Porém, 0 professor precisa ser preparado para lidar com essa nova realidade da educação brasileira e a sua formação inicial no curso superior precisa contemplar o uso das TIC sob seu aspecto didático-pedagógico, para se tornar uma ferramenta importante na aplicação de metodologias que aperfeiçoem e dinamizem 0 aprendizado dos conteúdos geográficos (SILVA, 2015, p. 29). 
A internet é um importante recurso tecnológico que através de um conjunto de redes de computadores integram pessoas, atividades e serviços, independentemente das adversidades naturais e localizações geográficas. Sua aplicabilidade tem ganhado notoriedade no âmbito econômico, cultural e educacional, viabilizada pela dinâmica e suas múltiplas interfaces, às quais devem estar integradas e não indiferentes a essa realidade, marcada pela inovação e por essa onda de informações instantâneas e acessíveis à grande parte da sociedade. Assim, no momento em que:

[...] se vivencia o período técnico-científico-informacional, não tem como dissociar educação e novas tecnologias, seja no ambiente escolar (currículo formal) ou cotidianamente (currículo informal), visto que, cada vez mais cedo, os jovens vêm utilizando tecnologias. A internet, por exemplo, disponibiliza uma infinidade de informações e pode ser utilizada como recurso pedagógico no auxílio do ensinar-aprender (PENHA; MELO, 2016, p. 117).

Nesse sentido, a internet permite a análise e a escolha de diferentes formas de aprendizagem, fazendo uso dos recursos como interfaces que complementam as aulas e dão suporte teórico através de estudos científicos encontrados nos meios eletrônicos, utilizados para a realização de trabalhos de natureza bibliográfica.

Ademais, quando a escola propõe fazer uso dessa tecnologia, as aulas ministradas tendem a atrair os alunos, em virtude das práticas pedagógicas inovadoras, o que pressupõe um trabalho voltado a incentivar os discentes ao desenvolvimento de pesquisas que priorizem não apenas as informações atuais, mas também fatos históricos e outras culturas. Nessa perspectiva,

[...] a geografia escolar enquanto componente curricular na Educação Básica também pode contribuir para atender estas finalidades. Um ensino que oportuniza a formação intelectual e a autonomia do estudante, para que este esteja realmente preparado para enfrentar as contradições que marcam a sociedade no atual período histórico do capitalismo, bem como do desenvolvimento do pensamento crítico e reflexivo, com capacidade de compreender o seu próprio contexto social (HOHN; SIMÕES, 2018, p. 10 11).

Dessa forma, a necessidade de um ensino de Geografia pautado na construção do conhecimento deve considerar não somente estudos realizados em livros impressos, mas também através das interfaces tecnológicas, pois a relação que os alunos mantêm com os artefatos digitais pode facilitar o desenvolvimento de estratégias pedagógicas, nas quais educadores e educandos podem interagir nesse espaço virtual, participando de grupos de discussão ou elaborando projetos na área da educação, ou, ainda, criando sites ou 
pesquisando temas de interesse coletivo que possam ser utilizados em estudos que promovam aprendizagem. Pois, conforme apontam Menezes e Kaercher (2017, p. 145):

A contemporaneidade tem revelado um mundo cada vez mais [...] dinâmico e mutável. [...] O turbilhão de informações que recebemos diariamente, 0 surgimento de novas tecnologias e as novas demandas da sociedade fazem com que os sujeitos sejam surpreendidos pelo ritmo acelerado da vida cotidiana.

Nessa perspectiva, evidenciam-se as inúmeras contribuições da Geografia como disciplina que pode desenvolver o senso crítico e a criatividade, inclusive a partir das interfaces tecnológicas que tendem a favorecer o processo de aprendizagem, permitindo de forma rápida e mais dinâmica o acesso à pesquisa relativa a diversos assuntos que são abordados, incluindo os temas geográficos. Além disso,

[...] é importante [...] que os profissionais da educação entendam que as novas tecnologias vinculadas a novas metodologias de ensino podem auxiliar na sua prática pedagógica, ajudando a despertar o interesse e a criatividade dos alunos quanto aos conteúdos estudados e, assim, contribuir para que os conhecimentos sejam compartilhados e construídos em meio a cooperação e tornar a aprendizagem mais significativa (PENHA; MELO, 2016, p.127).

Assim, utilizar a internet no ensino significa aproveitar um universo de informações e de pesquisas, no qual educadores e educandos podem vivenciar uma comunicação aberta, cuja participação é mútua, colaborativa e pedagógica, pois nesse processo de interação aprende-se e contribui-se com novos conhecimentos. E, dessa forma,

O ensinar e aprender acontece numa interligação simbiótica, profunda, constante entre o que chamamos mundo físico e mundo digital. Não são dois mundos ou espaços, mas um espaço estendido, uma sala de aula ampliada, que se mescla, hibridiza constantemente. Por isso a educação formal é cada vez mais blended, misturada, híbrida, porque não acontece só no espaço físico da sala de aula, mas nos múltiplos espaços do cotidiano, que incluem os digitais. $O$ professor precisa seguir comunicando-se face a face com os alunos, mas também digitalmente, com as tecnologias móveis, equilibrando a interação com todos e com cada um (MORAN, 2015, p. 16).

Nesse contexto, as tecnologias digitais integradas à internet permitem novas possibilidades de aprendizagem, dando ao aluno a condição de não só trilhar seu próprio caminho em termos de pesquisas educacionais, como também de explorar sua capacidade nesse mundo virtual que evidentemente é real ao proporcionar conhecimento.

Dessa forma, será importante planejar as aulas numa perspectiva de aproximar as tecnologias digitais das atividades pedagógicas, pois estas devem contemplar essa realidade em que há uma forte presença de instrumentos tecnológicos na escola e que pode 
influenciar o educando no modo de agir, de se comunicar e de aprender através das pesquisas realizadas na internet.

Em uma pesquisa de campo, desenvolvida na Escola Estadual professora Ocila Bezerril, no município de Montanhas - RN, foi aplicado um total de 100 questionários aos alunos que cursam o $1^{\circ}$ ano do Ensino Médio, tanto do turno matutino quanto do noturno. As questões formuladas buscaram verificar a utilização ou não da internet como recurso tecnológico que possibilita aprendizagem em Geografia.

A pesquisa revelou que a utilização da internet é uma prática constante na vida cotidiana dos alunos, inclusive no âmbito educacional, uma vez que tal recurso serve como subsídio para complementar os estudos da disciplina. Nesse contexto, na figura 1 expõe-se o resultado sobre o questionamento levantado em relação ao uso da internet no cotidiano dos educandos.

Figura 1 - A utilização da internet no cotidiano dos educandos

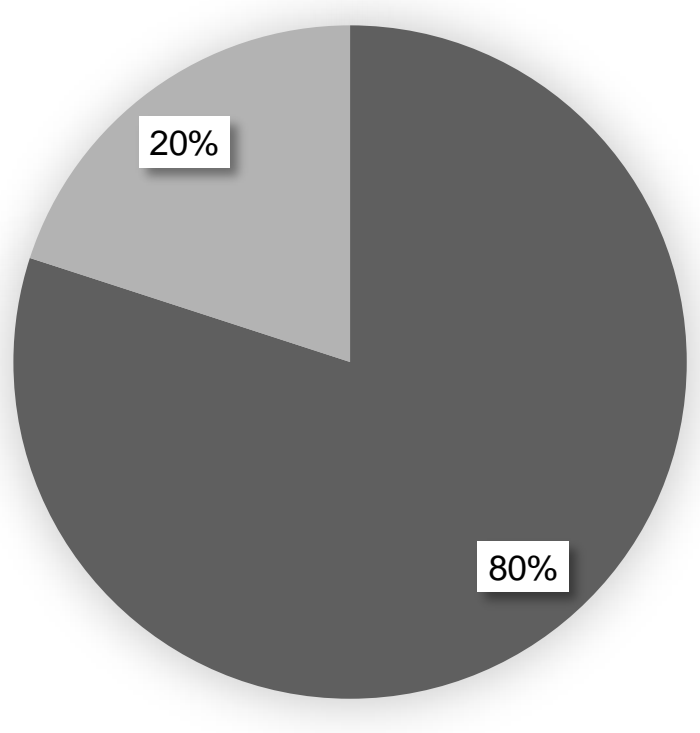

- Alunos que utilizam a internet

Alunos que não utilizam a internet

Fonte: o próprio autor.

Sobre a utilização da internet no cotidiano dos educandos, a figura 1 retrata uma realidade bastante comum nos dias atuais, onde os alunos se conectam facilmente à internet, e o percentual de estudantes que fazem uso deste recurso tecnológico voltado para o contexto educacional soma um total de $80 \%$. 
Outro ponto questionado refere-se ao fato de os professores orientarem ou não a realização de pesquisa no âmbito da Geografia, tendo como subsídio a internet. Sobre essa questão, $64 \%$ dos discentes afirmaram não receberem qualquer encaminhamento quanto ao desenvolvimento de estudos sistematizados, tendo como fonte de pesquisa a internet, conforme exposto na figura 2.

Figura 2 - Orientação dos docentes para pesquisas na internet

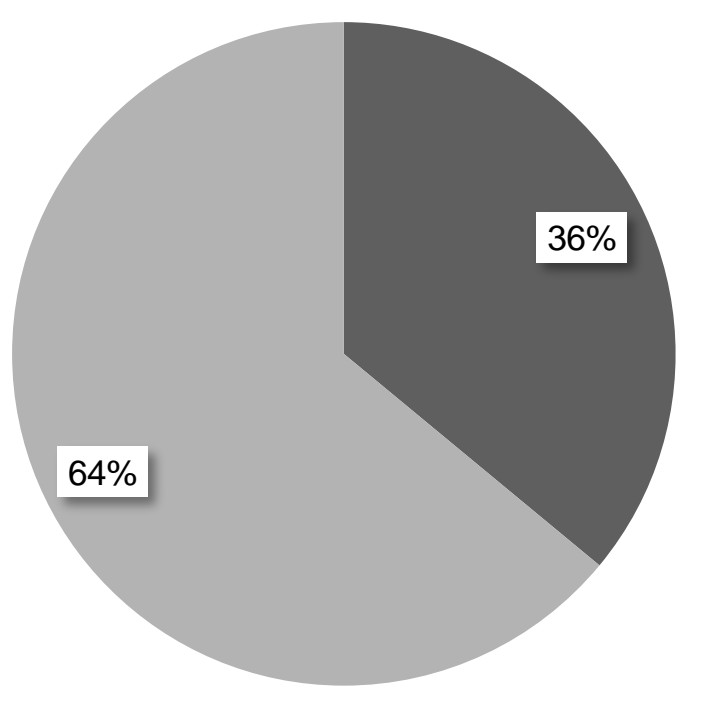

- Os docentes orientam os alunos

- Os docentes não orientam os alunos

Fonte: o próprio autor.

A pesquisa pertinente ao gráfico 2 reflete uma realidade em que a utilização da internet ainda não é uma prioridade educacional no âmbito da Geografia, de forma sistematizada, tendo em vista a falta de orientação para pesquisas numa perspectiva educacional.

Num mundo de tantas informações, a qualidade da docência se manifesta na orientação e na combinação do trabalho em grupo, incentivando a colaboração entre todos. $\mathrm{E}$, nesse processo, a internet facilita a aprendizagem colaborativa entre colegas próximos e distantes, pois cada vez mais adquire importância a comunicação entre os alunos, na troca de informações ou na realização de projetos (MORAN, 2015).

Assim, enquanto recurso didático tecnológico, a internet pode favorecer o ensino e, ao mesmo tempo, proporcionar conhecimento, tendo em vista a diversidade das interfaces 
tecnológicas, como o e-mail, o chat e o blog, entre outros, o que possibilita a integração e a troca de experiências, seja escrevendo, interagindo ou simplesmente como leitores.

O gráfico 3 , relativo à aula de Geografia e sua relação com a pesquisa realizada na internet, mostra que houve significativo posicionamento dos estudantes, pois $86 \%$ responderam ser a favor dessa relação no âmbito educacional.

Figura 3 - A aula de Geografia e sua relação com a pesquisa na internet

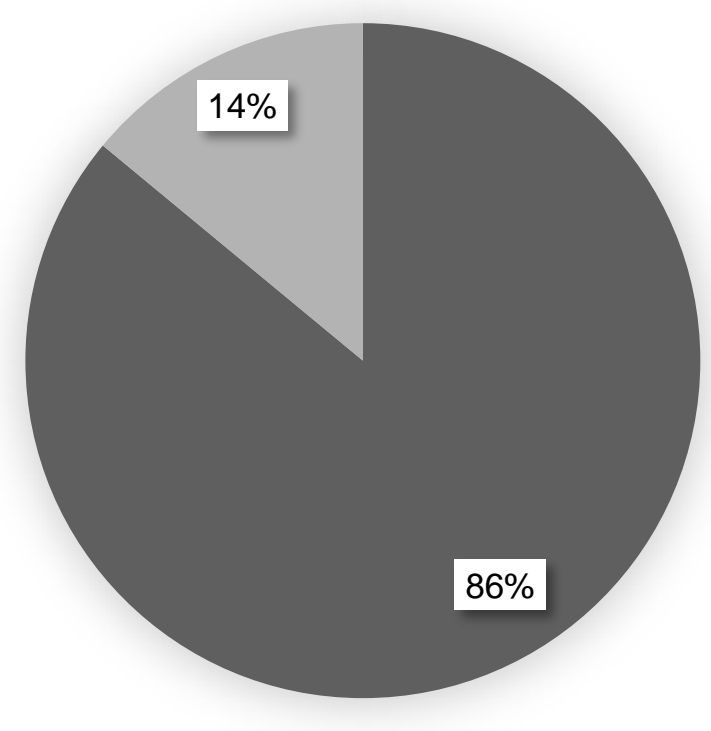

- Estudantes que são a favor dessa relação no âmbito educacional

Estudantes que são contra a essa relação no âmbito educacional

Fonte: o próprio autor.

Pela análise dos dados, fica nítida a posição dos estudantes sobre a viabilidade da interação entre a aula de Geografia com as pesquisas realizadas na internet, como forma de complementar a aprendizagem, tendo em vista que não é mais possível desenvolver um planejamento fechado, sem considerar outras possibilidades, já que no cenário atual se faz necessário não apenas utilizar esse mundo virtual como recurso de pesquisa, como também usufruir das várias interfaces que a internet oferece, seja através da participação em chat, blogs ou outros ambientes virtuais que despertem interesse e motivação para se aprender com qualidade. Nesse sentido,

[...] o ensino de Geografia alia-se à dimensão do conhecimento proporcionado pela escola, pois é uma disciplina que trata em seus conteúdos questões do mundo e da realidade atual e pode oferecer, a partir dos seus conceitos, ferramentas intelectuais para que o aluno possa 
entender o mundo a partir do lugar em que vive. Essas são possibilidades pela via da educação escolar e da Geografia para a transformação da realidade social dos alunos (DEON; CALLAI, 2018, p. 287).

A Geografia é uma disciplina que pode promover a dinamicidade, a criatividade e uma visão crítica sobre o uso das tecnologias digitais nas atividades pedagógicas. Por isso, o professor precisa estimular o aluno ao aprendizado a partir do conteúdo trabalhado e dos recursos didáticos utilizados, o que pode contribuir para o engajamento dos estudantes na aula. Pois,

\begin{abstract}
Dentre as grandes mudanças registradas na evolução das tecnologias digitais, está a rapidez com que as informações são difundidas, diferentes dos livros e jornais, que além do tempo da escrita e preparação do conteúdo, tem o tempo da impressão e distribuição física do mesmo. Essa quebra de barreira do tempo e espaço, proporcionada pela comunicação digital através das plataformas virtuais e redes sociais tem produzido radicais transformações nas relações pessoais, que podem ser tanto presenciais como virtuais, porém, quando se fala de aprendizagem e construção do conhecimento é importante que se saia da superficialidade e se possa problematizar e também desconfiar do que se encontra na rede (PEREIRA, 2017, p. 43 - 44).
\end{abstract}

De fato, a internet proporciona maior facilidade na troca de informações, mas antes é preciso que haja seleção das informações, visando considerar as que são úteis e que podem ser transformadas em conhecimento, o que se configura num fator relevante para a educação, pois aos poucos elimina a ideia de que a aprendizagem se dá apenas no espaço físico restrito à sala de aula. Esta continua sendo um ambiente de aprendizagem onde o professor encaminha as atividades que podem ser desenvolvidas com recursos tecnológicos disponíveis em casa ou em outros espaços de socialização.

Nessa perspectiva, o que se espera da escola e da Geografia não é apenas o conteúdo exposto pelo currículo, mas um conteúdo que propicie significativa aprendizagem aos educandos, instruindo-lhes para lidar com diferentes situações e linguagens tecnológicas, tanto na escola como em outros ambientes sociais. Essa meta a ser alcançada não deve se basear em grandes projetos extraídos de outras realidades, mas da vivência da instituição na qual se encontram educadores e educandos. Assim,

Se queremos que os alunos sejam proativos, precisamos adotar metodologias em que os alunos se envolvam em atividades cada vez mais complexas, em que tenham que tomar decisões e avaliar os resultados, com apoio de materiais relevantes. Se queremos que sejam criativos, eles precisam experimentar inúmeras novas possibilidades de mostrar sua iniciativa (MORAN, 2015, p. 17).

Nesse processo, ensinar utilizando a internet requer, portanto, metodologias diferentes da convencional, pois o professor não é mais aquele que centraliza todo o conhecimento e, 
sob essa ótica, será necessária a criação de ambientes de aprendizagem colaborativos que proporcionem a participação e a socialização de dados e informações pertinentes à matéria de estudo.

Nesse contexto, se o professor se esquivar de estimular ou criar novas estratégias que levem à aprendizagem, não promoverá o conhecimento. Se o professor que recebe alunos de diferentes condições socioeconômicas não lhes ensina a conviver com diferentes ambientes educacionais, não provocará interesse pelas suas aulas, pois lhes faltam motivação.

Ensinar com as novas mídias pressupõe uma mudança significativa, se efetivamente servir para aproximar professores e alunos em um processo de interação que permite avaliar e reavaliar pontos de vista e atitudes, bem como fazer ajustes no programa da disciplina e repensar nas formas de ensinar e de aprender. Assim,

O caminho é formar o professor para uma prática-reflexiva e torná-lo um investigador dentro da sala de aula, capacitado para identificar os problemas de aprendizagem e as oportunidades para melhorar sua prática e estimular a aprendizagem, em específico da disciplina de Geografia (SILVA, 2015, p. 34).

Ademais, é preciso que o professor se engaje em atividades que levem os alunos a refletir sobre seu papel como estudante para, a partir disso, também se envolver na cultura da informática, discernindo sobre os aspectos relevantes ou negativos que a internet oferece. Para isso, antes do docente ensinar utilizando este recurso, precisa estar preparado, orientando como pesquisar, selecionar e interpretar as informações disponíveis.

Em síntese, o professor de Geografia deve priorizar o uso dessa tecnologia voltada à educação, rompendo com aulas descontextualizadas para os alunos. Esse deve ser um objetivo constante em que a escola, a equipe pedagógica e o professor trabalhem coletivamente, promovendo conhecimento e despertando nos educandos o senso crítico para que possam ter acesso ao saber sistematizado e ser parte da cultura intelectual contemporânea, pois, como observa Menezes e Kaercher (2017, p. 151-152),

\footnotetext{
Em um processo de aprendizagem pautado nesta perspectiva, não basta que 0 aluno entre em contato com o conhecimento. Mais que isso, é necessário construir e (re)descobrir os conhecimentos. Assim, será possível desenvolver uma aprendizagem significativa. O professor, por sua vez, possui um papel importante neste processo, visto que deve provocar desacomodações e desequilibrações no pensamento do aluno. Deve problematizar a realidade, fazendo com que o educando questione o que está posto e desenvolva sua criticidade.
}

Dessa forma, o professor de Geografia precisa adaptar-se às novas mudanças tecnológicas, visando a utilização não apenas do livro proposto pela escola, mas também da 
internet, considerando, dentro deste espaço virtual, as possibilidades de aprender e compreender o espaço geográfico através de imagens de satélites, fotos e vídeos que facilitam o ensino e a aprendizagem.

Para tanto, é preciso que o professor determine objetivos e faça a seleção de assuntos ou temas que agucem a curiosidade dos alunos sobre o que se pretende ensinar e não meramente pelo uso da internet. Assim, o professor, além de incentivar os alunos a usufruir da internet como fonte de informação e de pesquisa, instrui-os à análise e à independência e, por conseguinte, à participação ativa no processo de aprendizagem.

Baseado nisso, o professor de Geografia assume no processo de ensino aprendizagem a função de interlocutor entre o aluno e a internet, sugerindo sites seguros e temas, cujas abordagens e referências sejam confiáveis e apresentem qualidade textual, pois a utilização dos recursos por si só não reflete conhecimento. E, portanto, se o educador não intervier diretamente nesse processo, haverá uma continuidade da cultura dominante, com indivíduos passivos e sem poder de reflexão.

\section{RECURSOS DISPONIBILIZADOS PELA INTERNET COMO INTERFACES NO PROCESSO ENSINO APRENDIZAGEM}

Os recursos disponibilizados pela internet apresentam inúmeras possibilidades de aprendizagem, o que permite facilitar as atividades pedagógicas no cotidiano escolar, a partir das interfaces que oferece, enquanto instrumentos de interação e de socialização entre alunos e professores.

Algumas das interfaces denominadas site, chat, blog e Ambiente Virtual de Aprendizagem (AVA) são bem conhecidas e permitem a formação de ambientes de encontro online no qual se pode organizar comunidades virtuais de aprendizagem. Neste espaço propiciam-se processos de integração, discussões temáticas de estudos, colaboração e descoberta.

Para tanto, os professores devem acompanhar as mudanças e se manterem atualizados, aperfeiçoando e desenvolvendo novas metodologias de ensino para que os alunos aproveitem da melhor forma possível esses instrumentos de aprendizagem. Pois, como salienta Moran (2015, p. 24),

As tecnologias permitem o registro, a visibilização do processo de aprendizagem de cada um e de todos os envolvidos. Mapeiam os progressos, apontam as dificuldades, podem prever alguns caminhos para os que têm dificuldades específicas (plataformas adaptativas). Elas facilitam como nunca antes múltiplas formas de comunicação horizontal, em redes, em grupos, individualizada. É fácil o compartilhamento, a coautoria, a publicação, produzir e divulgar narrativas diferentes. A combinação dos ambientes mais formais com os informais (redes sociais, wikis, blogs), feita 
de forma inteligente e integrada, nos permite conciliar a necessária organização dos processos com a flexibilidade de poder adaptá-los à cada aluno e grupo.

Assim sendo, não adianta o espaço escolar estar dotado de ferramentas tecnológicas, se as concepções sobre aprendizagem permanecem fechadas, sem conexão com este ambiente virtual que está aberto a novas possibilidades e que precisa ser incorporado na educação, com professores capazes de modificar e criar condições efetivas de aprendizagem. Por esta razão, necessitam apropriarem-se dessas interfaces tecnológicas, não somente para realização de tarefas, mas também para estimular os alunos na compreensão da realidade que os cerca.

Dessa forma, o papel do educador é o de "[...] contribuir para o crescimento (no sentido amplo do termo: intelectual, cognitivo, afetivo...) do educando para a sua autonomia, a sua criatividade e senso crítico" (VESENTINI, 2018, p. 24 - 25). Por isso, é importante que as práticas pedagógicas sejam planejadas para que as tecnologias digitais possam proporcionar aprendizagem em Geografia. A partir disso, entende-se que as Tecnologias Digitais da Informação e Comunicação - TDIC:

[...] precisam ser consideradas como recursos pedagógicos e, como tal, necessitam ser conhecidas e exploradas, pois apresentam-se em diversos suportes tecnológicos, tais como: desktops, laptops, notebooks, tablets, celulares, relógios e outros tantos que surgirão. Somente esses suportes não proporcionam mudanças significativas no processo de ensinoaprendizagem, o que proporcionará a efetiva mudança é a utilização das tecnologias presentes neles, com intenção de aprendizagem, ou seja, com planejamento, com projeção de possíveis resultados, como utilizar e principalmente a liberdade de escolha das tecnologias pelo usuário (PEREIRA, 2017, p. 84).

Nesse contexto, os instrumentos de aprendizagem vinculados à internet constituem recursos didáticos que possibilitam aos educadores atuarem no sentido de que o educando deixe de ser passivo e torne-se um cidadão ativo e crítico, portanto, emissor de ideias e não apenas receptor de informações. Este é um desafio e o professor de Geografia precisa estar atento a essa realidade, a fim de que a educação passe por uma transformação em que os alunos sejam os maiores beneficiados, sendo o docente o mediador desse processo. Tal mediação:

[...] torna-se de grande relevância quando se analisa a enorme quantidade de informações disponíveis na internet, pois localizar dados utilizando buscadores é uma tarefa a qual a maioria dos jovens já sabe realizar com habilidade. No entanto, conectar estas informações e transformá-las em conhecimento é ainda uma habilidade que precisa ser desenvolvida (TONETTO; TONINI, 2015, p. 91). 
A ideia é propor atividades dinâmicas capazes de estabelecer uma relação de aprendizagem a partir das variadas formas de linguagem disponibilizadas por essa mídia. Como exemplo, existem alguns softwares que podem ser acessados facilmente como o Google Maps e o Google Earth. Estes fornecem imagens que permitem análises sobre determinados pontos do território, o que possibilita ao professor ministrar aulas mais dinâmicas para os alunos, tendo em vista que poderão localizar diferentes lugares do espaço geográfico, bem como relacionar os assuntos da disciplina com dados e fenômenos espaciais fornecidos a partir desses softwares.

Outra possibilidade de utilização dos aplicativos Google Maps e Google Earth na disciplina de geografia diz respeito à prática de atividade relacionada ao estudo do meio, pois a utilização das imagens de satélites auxilia na realização de roteiros de trabalho de campo, sendo possível identificar e visualizar paisagens naturais e culturais, e as informações obtidas pelas imagens permitem aos alunos fazer associações entre o estudo desenvolvido em sala de aula com as imagens observadas em tempo real. Porém,

É necessário que além de usar as TDIC, o professor saiba o que essa mediação está proporcionando para o estudante, pois o processo de construção do conhecimento se dá a partir da relação entre o sujeito e o objeto, ou seja, as informações que são adquiridas através da vivência e da aprendizagem vão sendo reelaboradas por cada estudante, que as interrelacionam construindo suas próprias sínteses (PEREIRA, 2017, p. 145).

Desse modo, devem-se viabilizar condições de acesso a essas novas formas de mediação tecnológica, que não ocorre apenas na escola, mas também fora dela. Analisar essas questões facilita as ações do docente no que se refere ao planejamento de suas aulas e seus objetivos em termos educacionais, já que muitos alunos fazem uso de alguns recursos da internet sem qualquer visão crítica sobre eles. Por isso, entende-se que:

Com formação adequada, o professor será capaz de superar o uso das novas tecnologias como suporte e defini-las não só como material didático tendo em vista a construção de atividades que viabilizem a aprendizagem, mas como uma nova forma de relacionar-se com o conhecimento, individualmente e de forma colaborativa, compartilhando aprendizagens (KUENZER, 2016, p. 34).

Sob esse contexto, os professores necessitam propor questões de pesquisas vinculadas à educação, visando analisar e discutir sobre as informações e as imagens veiculadas na internet, bem como ainda sobre as diversas formas de interação social como os serviços de e-mails, chats e blogs, entre outros, que contribuem não só para as relações interpessoais, como também para o desenvolvimento da escrita e da leitura. 
Os e-mails são recursos que, do ponto de vista didático, proporcionam a comunicação entre alunos e professores através da escrita e abrangem diferentes assuntos. E, como recurso, possibilita não somente a linguagem escrita, como disponibiliza o envio de arquivos, fotos, vídeos etc., em um tempo rápido e instantâneo, podendo tornar-se um instrumento estratégico no desenvolvimento de atividades escolares, cabendo ao usuário o acesso ao conteúdo por meio de uma simples conexão com a internet.

Os chats também disponíveis na internet possibilitam relações sociais via campo virtual em tempo real, através de mensagens escritas, pois é possível a troca de informações e diálogos simultaneamente, tendo em vista que seus usuários interagem em grupos de discussões voltados, às vezes, ao entretenimento, separados por temas e por interesses específicos, tais como meio ambiente, profissões, cidades e cultura, entre outros.

Vale ressaltar, ainda, que os chats, além do entretenimento, são utilizados nas empresas particulares e nas instituições públicas, a exemplo das universidades, que mantém cursos à distância e que criam suas próprias estratégias para melhor interagir em assuntos relacionados ao ensino e à aprendizagem, graças à dinâmica e ao intercâmbio que proporciona a discentes e docentes.

Assim, pode-se atuar no sentido de eliminar barreiras, superar a timidez que ocorre em sala de aula e propiciar uma maior participação nesse espaço online de aprendizagem, pois, enquanto recurso, o chat se constitui num instrumento útil ao possibilitar entre professores e alunos a construção conjunta do conhecimento.

Outro importante recurso que pode ser apreciado no sistema de ensino refere-se ao blog, uma forma de interação bastante conhecida, no qual se desenvolve a escrita e a leitura através dos textos. Estes, geralmente estão acompanhados por fotos que ilustram o tema ou notícia publicada, se constituindo num diário online onde se registra informações. E como diário "[...] é utilizado como meio de comunicação e informação nos diversos campos sociais. No meio educacional, o blog também é usado como recurso didático por professores que buscam dinamizar suas aulas" (DUARTE; MAFRA, 2016, p. 33).

Dessa forma, o professor pode propor a criação desse diário eletrônico, visando registrar temas de estudo da disciplina de Geografia que possam ser explorados pelos alunos. A produção de conhecimentos pode ser organizada em grupos de trabalho, de modo planejado e por meio do estudo de textos que levem à discussão, à análise e à contextualização do assunto no cotidiano da sala de aula.

Assim, ao incentivar o uso deste recurso, fomenta-se não só a comunicação entre docentes e discentes, mas se favorece a organização de tarefas escolares inovadoras e atraentes ao processo de estudo, o que pode contribuir para novas metodologias e um melhor aproveitamento dos conteúdos exigidos na disciplina. Entretanto, o blog não é 
utilizado apenas como fonte de pesquisa, mas como ferramenta que permite aos alunos tornarem-se autores e leitores da sua própria produção, publicando vídeos, mapas ou conteúdos que permitam a mediação entre este recurso e o ensino de Geografia.

Outra proposta de trabalho interessante na disciplina de Geografia refere-se ao ensino baseado na metodologia da sala de aula invertida, onde os alunos, antes de discutirem um assunto, buscam conhecer o material disponibilizado pelo docente para posteriormente problematizar situações reais. Essa prática de ensino se constitui num processo no qual:

[...] se emprega a tecnologia para inverter o papel tradicional do tempo de aula, aqui os alunos são expostos a conceitos fora da sala de aula, geralmente através da observação e análise de vídeos. O tempo de sala de aula é então utilizado para fazer o difícil trabalho de assimilar esses novos saberes, através de estratégias como a resolução de problemas, discussão ou debates, sendo integralmente dedicado a experiências de aprendizagem ativas. Assim, recorrendo ao uso de tecnologias na partilha de dúvidas e curiosidades, a organização da sala de aula altera-se, passando os aprendentes para a posição central, previamente ocupada pelo professor, promovendo uma maior dinâmica em sala de aula (CARVALHO; RAMOS, 2015, p. 370).

Sob esse entendimento, o docente encaminha as atividades para que o aluno tenha um primeiro contato com a proposta sugerida, um trabalho com vídeos ou leituras, por exemplo, para na sequencia desenvolver os conhecimentos em sala de aula, pois uma das formas "[...] mais interessantes de ensinar hoje é o de concentrar no ambiente virtual o que é informação básica e deixar para a sala de aula as atividades mais criativas e supervisionadas. É o que se chama de aula invertida" (MORAN, 2015, p. 22).

Nesse sentido, essa metodologia pode ser utilizada para desenvolver processos educacionais flexíveis e colaborativos em consonância com as interfaces tecnológicas viabilizadas pela internet, na qual o aluno deve não só assimilar o conteúdo, mas principalmente ser um sujeito consciente, ativo e reflexivo sobre seu processo de formação.

Nessa perspectiva, reitera-se a importância dos recursos tecnológicos nas aulas de Geografia, tendo em vista as potencialidades oferecidas e que representam uma forma contemporânea de aprendizagem mediada por processos interativos e digitais.

\section{CONSIDERAÇÕES FINAIS}

O artigo em questão teve como propósito abordar práticas pedagógicas e metodologias dinâmicas, visando uma forma inovadora de ensinar, em consonância com o uso da internet nas aulas de Geografia.

A pesquisa buscou investigar como a internet contribui para o processo ensino aprendizagem, tendo em vista ser uma ferramenta didática tecnológica importante, que pode 
corroborar para o desenvolvimento da autonomia e da criticidade, por meio de atividades que incentivem a interação entre educadores e educandos no ambiente escolar.

Nesse sentido, se o professor não propiciar meios de aprendizagem aos discentes, incluindo a internet, não promoverá a reconstrução do conhecimento e da experiência dos alunos através dessa ferramenta de aprendizagem. E, se o ensino se converter numa simples rotina que preenche algumas horas diárias, descontextualizado da realidade e dedicado apenas a assimilar conhecimentos sem análise e participação crítica, não possibilitará a verdadeira aprendizagem almejada pelos alunos.

Assim, é necessário que o docente repense sobre sua prática pedagógica para facilitar o trabalho e motivar os alunos nas aulas de Geografia, pois ele é o mediador que coordena as atividades e instiga a curiosidade, o questionamento e a reflexão em relação aos estudos realizados na disciplina. E, como disciplina, a Geografia contempla um leque de possibilidades de aprendizagem. Porém, para isso, é preciso que o docente proponha ideias que tenham relevância para os estudantes ao pesquisarem e utilizarem textos, mapas, imagens e aplicativos da internet em sala de aula.

Nesse contexto, o professor deve ter um olhar voltado para questões que compreendem o cotidiano dos alunos e que, portanto, fazem parte da sua realidade, vinculando o conteúdo da disciplina às tecnologias digitais, como forma de complementar as aulas e proporcionar conhecimento.

\section{REFERÊNCIAS}

CARVALHO, R. J. O.; RAMOS, M. A. S. Flipped classroom: centrar a aprendizagem no aluno recorrendo a ferramentas cognitivas. In: CONFERÊNCIA INTERNACIONAL DE TIC NA EDUCAÇÃO - CHALLENGES, 9., 2015, Braga, PT. Atas do [...] Braga: Universidade do Minho, 2015. p. 369-381.

DEON, A. R.; CALLAI, H. C. A educação escolar e a geografia como possibilidades de formação para a cidadania. Contexto \& Educação, ljuí, RS, Ano 33, n. 104, p. 264-290, jan./abr. 2018.

DUARTE, R. L.; MAFRA, M. P. V. O blog como recurso didático no ensino de Geografia: a experiência do geoeduc1.blogspot.com. Revista de Ensino de Geografia, Uberlândia, MG, v. 7, n. 12, p. 32-47, jan./jun. 2016.

HOHN. M. O.; SIMÕES, W. O ensino de Geografia em cursos técnicos de nível médio integrado: entre a formação intelectual e a formação para o mundo do trabalho. Geografia, Ensino \& Pesquisa, Santa Maria, RS, v. 22, p. 1-13, 2018.

KUENZER, A. Z. Trabalho e escola: a aprendizagem flexibilizada. Revista do Tribunal Regional do Trabalho da 10 ${ }^{\text {a }}$ Região, Brasília, DF, v. 20, n. 2, p. 13-36, dez. 2016.

MENEZES, V. S.; KAERCHER, N. A. Geografia e educação: uma discussão epistemológica. Geosul, Florianópolis, v. 32, n. 65, p. 144-158, set./dez. 2017. 
MORAN, J. Mudando a educação com metodologias ativas. In: SOUZA, C. A; MORALES, O. E. T. (org.). Convergências midiáticas, educação e cidadania: aproximações jovens. Ponta Grossa: UEPG-PROEX, 2015. p. 15-33.

PENHA, J. M.; MELO, J. A. B. Geografia, novas tecnologias e ensino: (re)conhecendo o "lugar" de vivência por meio do uso do google earth e google maps. Geo UERJ, Rio de Janeiro, n. 28, p. 116-151, 2016.

PEREIRA, A. M. O. O protagonismo do jovem na relação com o conhecimento geográfico: possibilidades e limitações no uso das tecnologias digitais nas aulas. Tese (Doutorado em Diversidade Cultural e Inclusão Social) - Universidade Feevale, Novo Hamburgo, RS, 2017.

SILVA, J. R. R. As tecnologias da informação e da comunicação no ensino de Geografia: formação e prática docente. Dissertação (Mestrado em Geografia) Universidade Federal de Uberlândia, Uberlândia, MG, 2015.

TONETTO, É. P.; TONINI, I. M. Ensinar e aprender Geografia com/nas redes sociais.

Giramundo, Rio de Janeiro, v. 2, n. 3, p. 87-96, jan./jun. 2015.

VESENTINI, J. W. Educação e ensino da geografia: instrumentos de dominação e/ou de libertação. In: CARLOS, A. F. A. (org.). A geografia na sala de aula. São Paulo: Contexto, 2018. p. 14-33.

Recebido: maio de 2019. Aceito: setembro de 2019. 